\title{
Shield tunnels connected to an operating station - a case study in Taipei MRT projects
}

\author{
J.F. Chang ${ }^{\text {i) }}$, C.R. Chou ${ }^{\text {ii) }}$, Y.F. Lai ${ }^{\text {i) }}$ and Y.H. Hsieh ${ }^{\text {iii }}$ \\ i) Senior Engineer, Moh and Associates, Inc., Oriental Technopolis Building A, 22 FL., No. 112, Xintai Wu Rd., Sec. 1, Xizhi District, \\ New Taipei City 22102, Taiwan, R.O.C. \\ ii) Deputy Manager, Moh and Associates, Inc., Oriental Technopolis Building A, 22 FL., No. 112, Xintai Wu Rd., Sec. 1, Xizhi District, \\ New Taipei City 22102, Taiwan, R.O.C. \\ iii) Deputy Director, North District Project Office Department of Rapid Transit System, Taipei City Government, 3 FL., No. 86, Ln. 527, \\ Daye Rd., Beitou District, Taipei City 11268, Taiwan, R.O.C.
}

\begin{abstract}
Due to degradation in quality of ground improvement during tunnel excavation, shield machines arriving at the receiving shafts have been one of the most risky works in soft ground tunnelling. The situation will become more challenging if the destination is not a shaft but an operating station. This paper illustrates a case study in the Taipei's Mass Rapid Transit (MRT) projects where, due to limited space and intricate pipeline system above the designed route, constructing a receiving shaft next to an operating station for shield tunnelling is not economically available. As a result, the tunnels should be connected to the station directly with limited protection from the improved ground that was implemented at the breaking area. The background of the study case is first briefed, including the restraints to keep the station in revenue operation. The construction procedure is then provided to delineate how the breaking-through process is incorporated with complementary grouting, machine disassembly, and lining erection. Through the results of the monitoring system that includes electronic instruments, the case is completed under reasonable control of construction-induced ground and structure deformations, dust, and etc. The operation of the station is not interfered at all over the breaking-through process.
\end{abstract}

Keywords: shield tunneling, arrival, operating station, breaking-through process

\section{INTRODUCTION}

Shield tunnels connected to an operating station is an inevitably challenge for soft ground engineering especially when the mass rapid transit (MRT) network becomes more and more wide-spreading. The station is connected for either transfer or extension purposes. While the complexity in constructing these two types of connections depends on the environmental constraints, such as geological and hydraulic conditions, and the layout of the existing structures and utilities, the extension type connection will directly face the operating trains and the associated facilities that require additional cautions during breaking-through process.

With the first line setting out for revenue operation in 1996, the Taipei Rapid Transit System (TRTS) has been developing its networks to five lines with a total of 116 stations and approximately $135 \mathrm{~km}$ of routes by the end of 2014 (DORTS, 2014) that facilitates the daily life of more than 2 million people in the metropolis. Among the 116 stations, there are 16 transfer stations and only limited, few terminal stations that were constructed through extensions. This paper illustrates one case study in the extension projects where the shield tunnels were connected directly to an operating terminal station rather than a receiving shaft to minimize the construction effects. The background and restraints to keep the station in operation is first briefed. The construction procedure is then described and shown how it is incorporated with complementary grouting, machine disassembly, and lining erection. Monitoring results are presented followed by conclusions given at the end of the paper.

\section{BACKGROUND}

The extension project is part of the Blue Line in the second stage of the TRTS developments that ranges from the current terminal station to a technical park in the south direction. The total length of the project is about $1,950 \mathrm{~m}$ including a $1,529-\mathrm{m}$-long bored tunnel section, a 421-m-long cut-and-cover section (i.e. one new terminal station and one crossover), and four cross passages in the tunnel section. The overburden of the tunnels varies from $13 \mathrm{~m}$ to $24 \mathrm{~m}$, and the geologic strata that tunneling would encounter are primarily gravels 


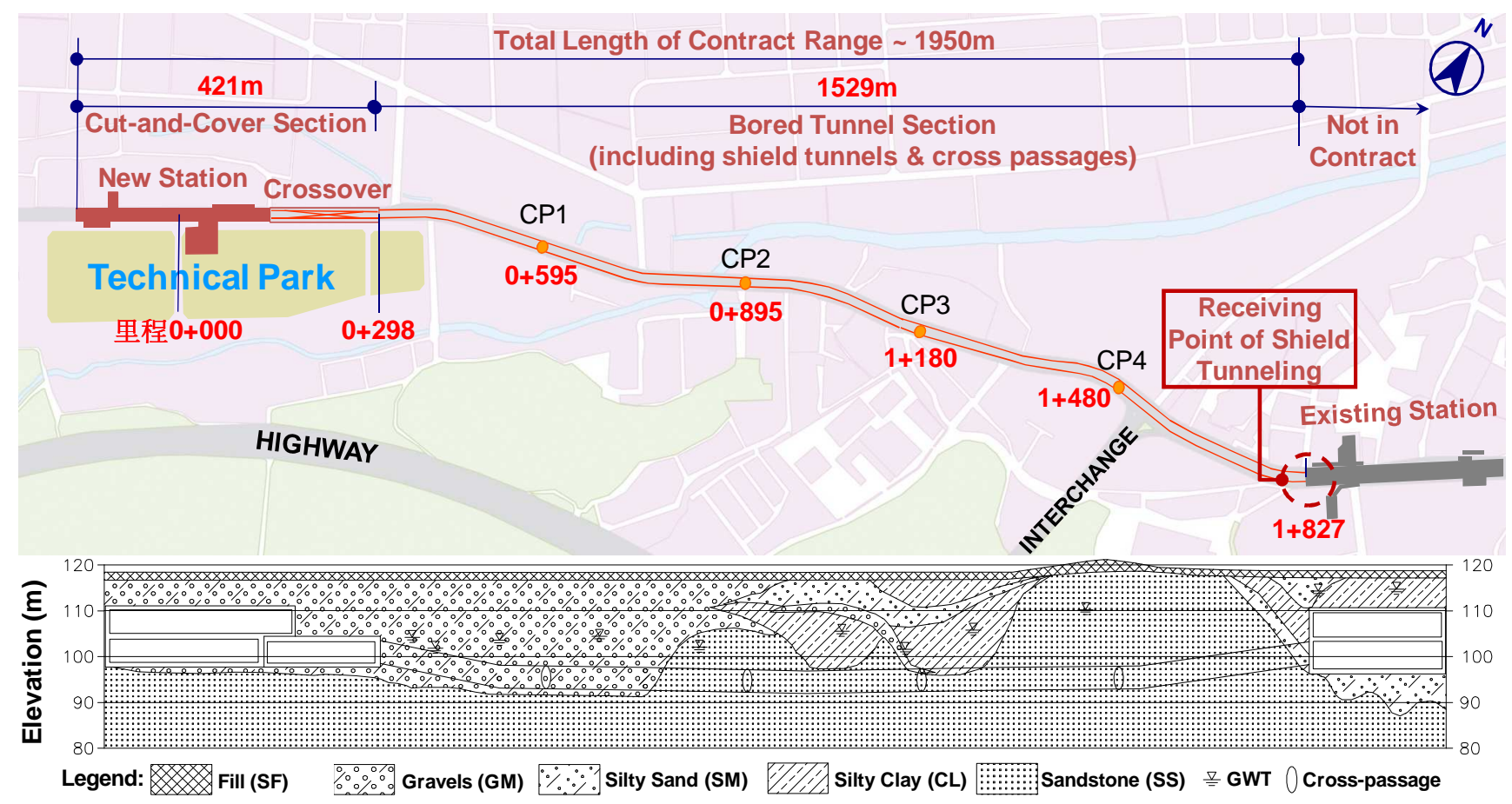

Fig. 1 Project range and schematic of soil profile along the project.

and sand stone. Alluviums (e.g. silty clays and sands) would only be encountered at the existing station area, as shown in Fig. 1. The groundwater level is about $11.3 \mathrm{~m}$ to $12.5 \mathrm{~m}$ deep below ground surface for most the site except for the existing station area where a level as high as $3 \mathrm{~m}$ to $4 \mathrm{~m}$ is anticipated. A hydrostatic pressure distribution over depths of consideration is obtained from the site investigation results (e.g. MAA, 2009).

As depicted in Fig. 1, the receiving point of the bored tunnels is concluded to set at the connection with the existing station based on the reports from the current and adjacent projects (e.g. MAA, 2008). As a result of the intricate and widespread pipelines that lie underneath the roadway at the receiving point however (Fig. 2), all the reports suggest constructing a receiving shaft be economically unavailable for arrival. As such, it is proposed to let shield machines drill directly into the station. Shield machines might further be disassembled in parts and leave the shields on the site. Since the whole disassembly process shall be

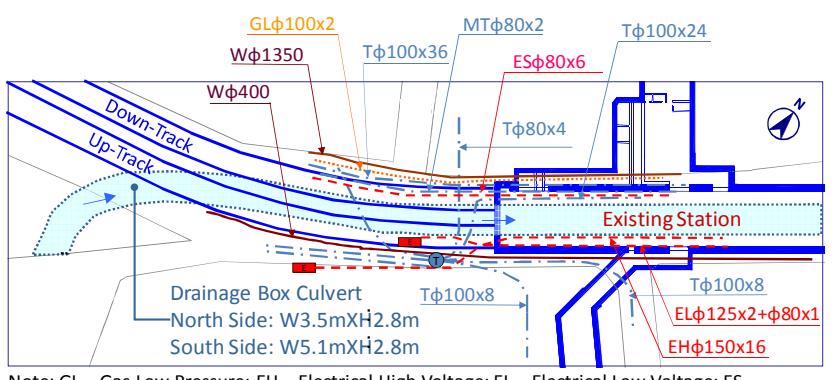

(a) $\mathrm{GL}$ - Gas Low Pressure; EH - Electrical High Voltage; EL - Electrical Electrical Super High Voltage; MT - Military Telephone; T - Public Telephone; W - Water Supply.

Fig. 2 Distribution of pipeline at the existing station. incorporated with the breaking-through process, the quality of the ground improvement that is implemented at the breaking area is more important than that used for general arrivals. A large-diameter jet grouting method (with the nominal diameter of the grout piles of at least $2.4 \mathrm{~m}$ ) is thus proposed to conquer the presence of the drainage box culvert right above the tunnels. Details of the large-diameter jet grouting (with the nominal diameter of the grout piles of $3.5 \mathrm{~m}$ ) are referred to Cheng et al. (2012). Fig. 3 shows the typical cross-section of the box culvert, tunnels, and the range of ground improvement.

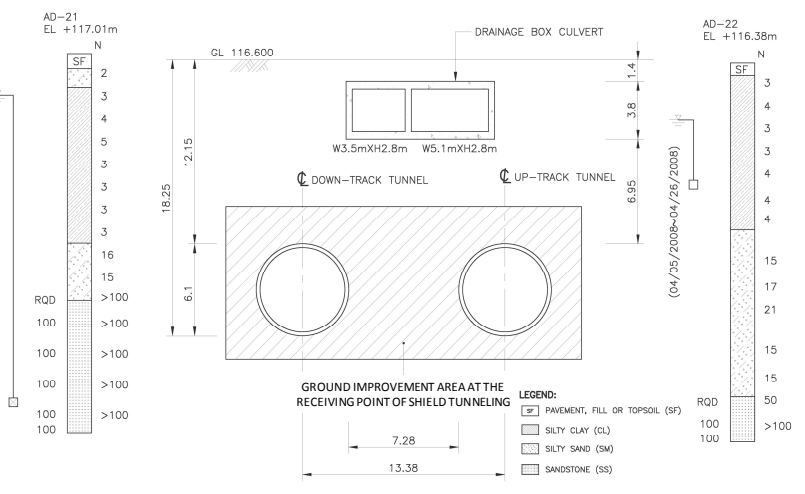

Fig. 3 Typical cross-section of shield tunneling at receiving.

In response to the direct drill of shield machines, protection measures were planned and installed at the breaking area during the construction of the existing terminal station. Fig. 4 illustrates that these measures primarily include a removable structure wall, a flood wall, and a dust-free, soundproof steel wall. Although 


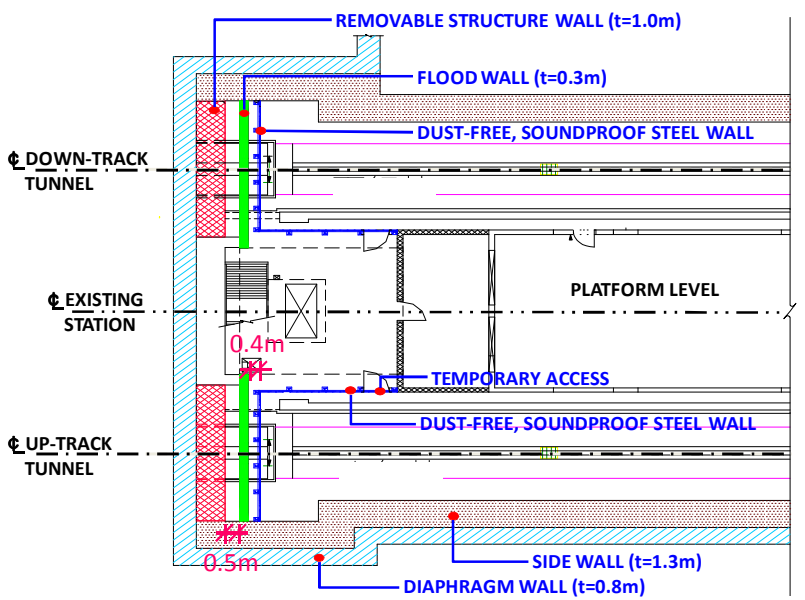

Fig. 4 Protection measures from direct break-through.

quantitative restraints were not given by the operating authority (i.e. Taipei Rapid Transit Corporation, TRTC), the principal restraints to keep the station in revenue operation are as follows.

(1) Personnel try to enter and exit the working area via the station access shall take training courses and be controlled by the passenger agent office (PAO).

(2) Flood walls can only be removed when flood protections are installed at the other end of the tunnels.

(3) Debris disposal via the station access is not allowed.

(4) Dust shall be kept in the working area and any disturbance to the station operation is not allowed.

(5) Heat, ventilation, and air-conditioning (HVAC) and electrical and mechanical (E\&M) systems in the station shall remain functional during the construction period.

\section{CONSTRUCTION PROCEDURE}

Incorporated with the restraints of TRTC in the last section, the construction procedure for arrival of tunneling machines was proposed and is briefed as follows.

(1) Shield machine drills through the improved ground and stops boring when the drill bits touch the diaphragm wall of the station.

(2) Empty soils in the chamber and setup scaffold for partial demolition of diaphragm wall.

(3) Disassemble cutter head.

(4) Machine is advanced into the diaphragm wall.

(5) Disassemble machine with shields left on site.

(6) Demolish diaphragm wall and structure wall.

(7) Erect linings, install flexible joints, and construct invert with track plinths installed.

(8) Remove flood wall and dust-free, soundproof steel wall.

To prevent excessive degradation in the quality of ground improvement during the process that would lead to soil and water infiltration, the advancing speed of the shield machine was controlled (in the improved ground: $\leqq 5 \mathrm{~mm} / \mathrm{min}$; in the diaphragm wall: $15 \sim 30 \mathrm{~mm} / \mathrm{min}$ ) and complementary grouting and water-tightness tests were conducted immediately after step (1) and (4) was completed. The grouting range was extended from the middle shield of the machine to 10 rings of linings outside the ground improvement area. On the other hand, the water-tightness tests were performed on the excavation face (up to the diaphragm wall) and along the circumference of the middle shield (with a depth of about $0.2 \mathrm{~m}$ ). Additional grouting may be required if the resulting coefficient of permeability $(\mathrm{k})$ from the tests is greater than $10^{-5} \mathrm{~cm} / \mathrm{sec}$.

In addition, diamond wire saws were introduced to reduce vibration and noise induced during wall demolition. The flowchart of the construction procedure is as sketched in Fig. 5, the associated timetable for the up- and down-track tunnels is as tabulated in Table 1, and the photos taken for the major steps of the procedure are as shown in Fig. 6.

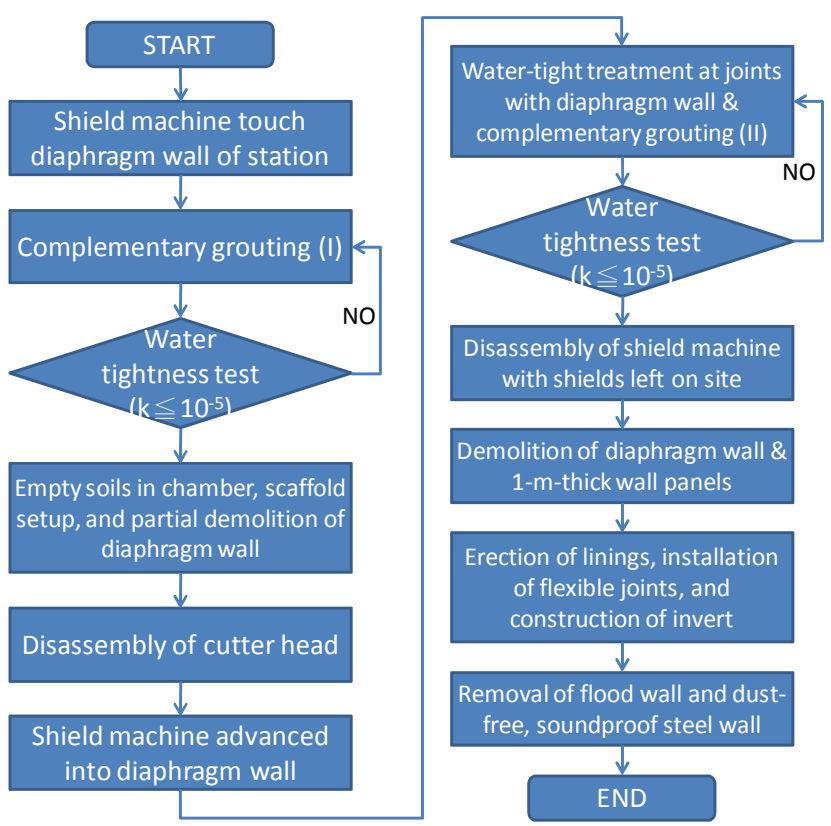

Fig. 5 Flowchart of construction procedure.

Table 1. Construction timetable for up- and down-track tunnels.

\begin{tabular}{lcc}
\hline \multicolumn{1}{c}{ Major construction event } & Up track & Down Track \\
\hline $\begin{array}{l}\text { (1) Shield machine touching improved } \\
\text { ground }\end{array}$ & $02 / 28 / 13$ & $01 / 18 / 13$ \\
\hline $\begin{array}{l}\text { (2) Shield machine touching diaphragm } \\
\text { wall }\end{array}$ & $03 / 02 / 13$ & $01 / 21 / 13$ \\
\hline $\begin{array}{l}\text { (3) Shield machine advancing into } \\
\text { diaphragm wall }\end{array}$ & $03 / 29 / 13$ & $03 / 14 / 13$ \\
\hline (4) Removal of diaphragm wall and & $04 / 18 / 13 \sim$ & $04 / 06 / 13 \sim$ \\
wall panel & $05 / 16 / 13$ & $04 / 28 / 13$ \\
\hline (5) Lining erection & $05 / 23 / 13 \sim$ & $05 / 08 / 13 \sim$ \\
& $05 / 29 / 13$ & $05 / 11 / 13$ \\
\hline (6) Installation of flexible joints & $05 / 31 / 13 \sim$ & $05 / 13 / 13 \sim$ \\
& $06 / 07 / 13$ & $05 / 24 / 13$ \\
\hline (7) Construction of invert and & $06 / 08 / 13 \sim$ & $05 / 25 / 13 \sim$ \\
installation of track plinths & $02 / 20 / 14$ & $02 / 20 / 14$ \\
\hline (8) Removal of flood wall & $02 / 21 / 14 \sim 03 / 12 / 14$ \\
\hline (9) Removal of dust-free, soundproof wall & $06 / 16 / 14 \sim 06 / 24 / 14$ \\
\hline
\end{tabular}




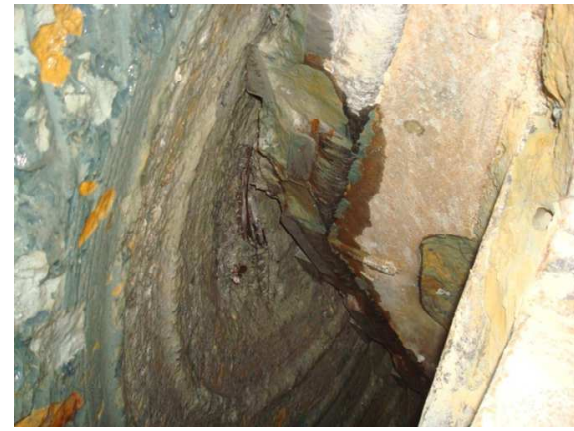

(a) Shield machine touching diaphragm wall.

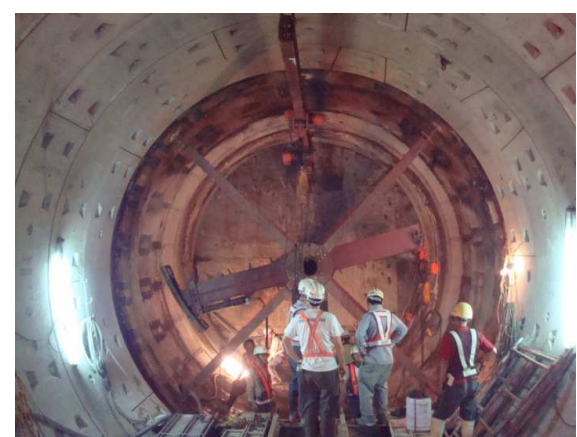

(d) Lining erection.

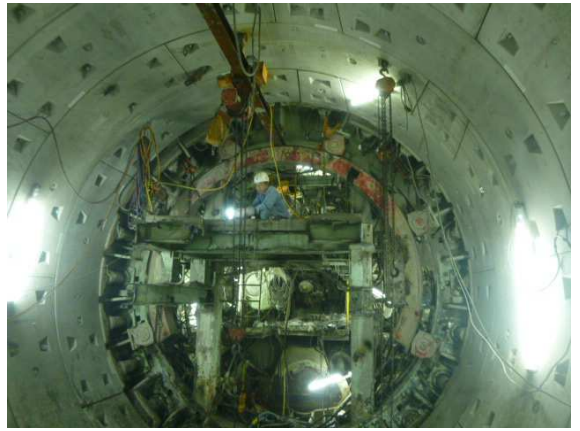

(b) Disassembly of shield machine.

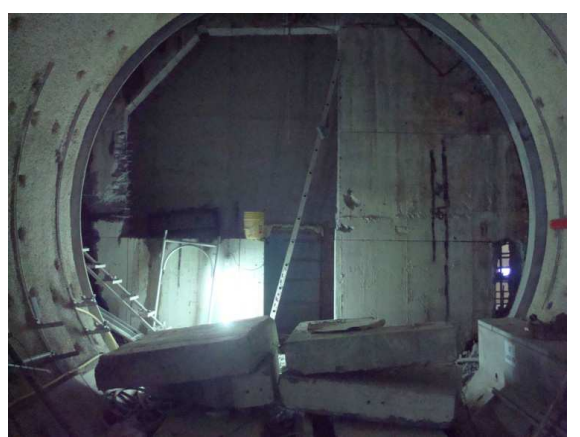

(e) Removal of flood wall.

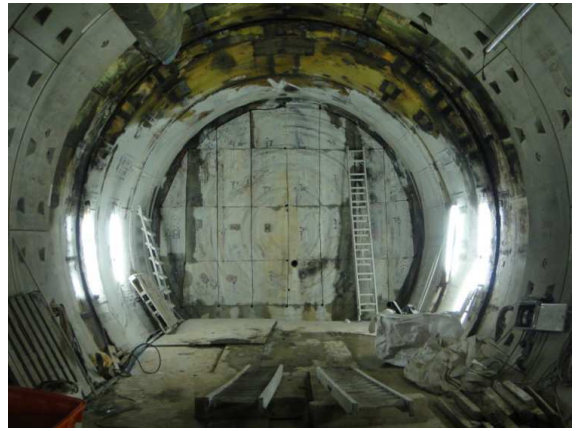

(c) Demolition of diaphragm wall and wall panel.

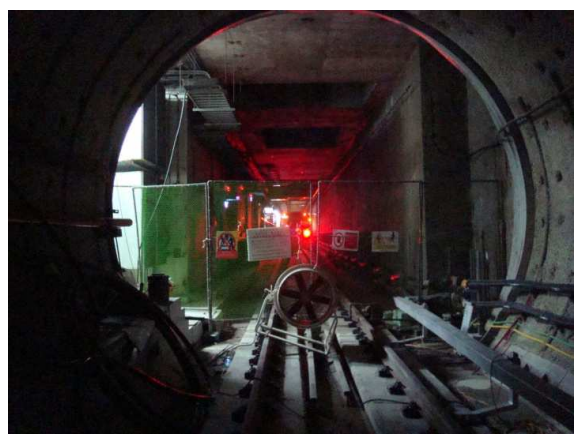

(f) Removal of dust-free, soundproof steel wall.

Fig. 6 Photos taken for major steps of construction.

\section{MONITORING RESULTS}

To observe the effects of breaking-through procedure on the operating station and provide immediate contingency measures to exceedingly large response, a thorough monitoring system was constructed. For the tunnel side, settlement points, rod extensometers, and inclinometers were installed to monitor at-grade and subsurface ground movements. Electronic piezometers were further installed to measure the groundwater tables at depths of tunneling. For the station side, electronic beam sensors and tiltmeters (Fig. 7) were mounted on the wall of the station to observe its movements and deformations. Fig. 8 depicts the layout of the instruments installed on the site, and a summary is listed in Table 2 with the associated response levels. The results obtained from electronic instruments are presented and briefed in the following paragraphs.

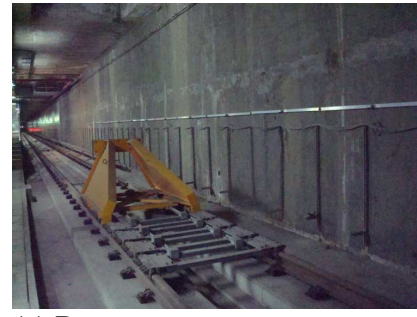

(a) Beam sensors

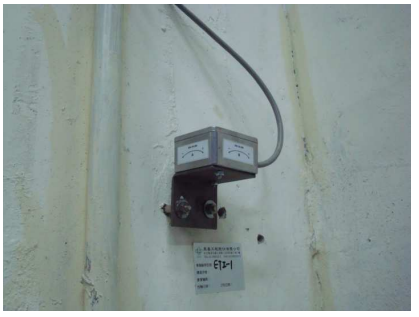

(b) Tiltmeter
Fig. 7 Electronic instruments installed for structure deformations.

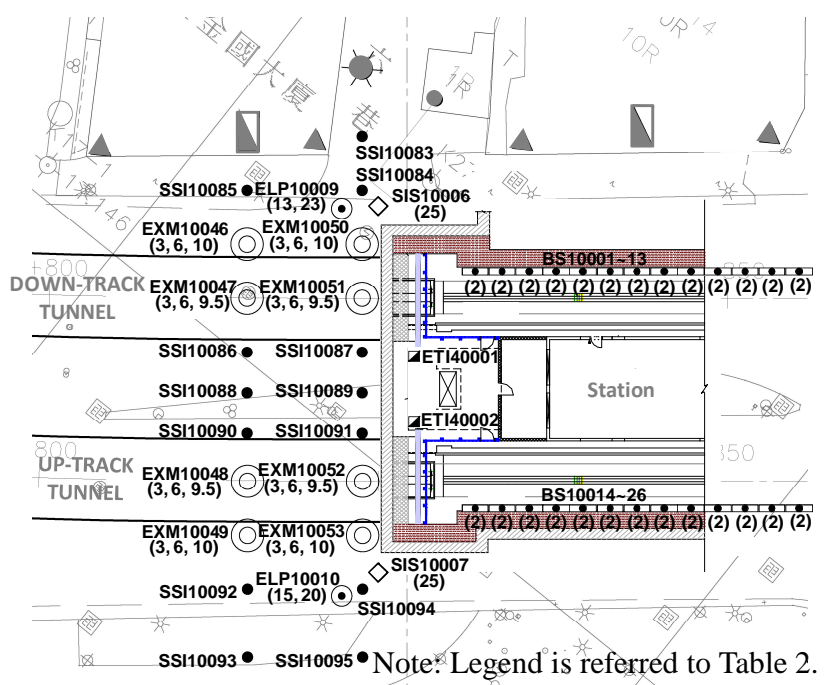

Fig. 8 Layout of monitoring instrumentation.

Fig. 9 shows the hydraulic pressure distribution over the construction period. From the figure, the initial readings corresponded reasonably to the groundwater condition depicted in Fig. 3. It is noted that a declined trend is derived right after the shield machines touched the diaphragm wall and holes had been drilled for water-tightness tests. A significantly large amount of clean water was further found flowing from the gaps between diaphragm wall and structure wall during the demolition process. The trend became stable and was gradually recovered when the water was diverted away and blocked during and after the process, respectively. 
Table 2. Summary of monitoring instrumentation.

\begin{tabular}{|c|c|c|c|c|c|c|}
\hline Item & $\begin{array}{c}\text { Monitoring } \\
\text { item }\end{array}$ & Instrument & Symbol & Abbre. & $\begin{array}{l}\text { Alert } \\
\text { level }\end{array}$ & $\begin{array}{l}\text { Action } \\
\text { level }\end{array}$ \\
\hline \multirow{3}{*}{1} & \multirow{3}{*}{$\begin{array}{l}\text { At-grade \& } \\
\text { subsurface } \\
\text { movement }\end{array}$} & $\begin{array}{c}\text { Rod } \\
\text { extensometer }\end{array}$ & $\mathbf{Q}_{(\mathrm{d})}$ & EXM & $\begin{array}{c}32 \\
\mathrm{~mm}\end{array}$ & $\begin{array}{c}40 \\
\mathrm{~mm}\end{array}$ \\
\hline & & $\begin{array}{l}\text { Settlement } \\
\text { point }\end{array}$ & & SSI & $\begin{array}{c}32 \\
\mathrm{~mm}\end{array}$ & $\begin{array}{c}40 \\
\mathrm{~mm}\end{array}$ \\
\hline & & $\begin{array}{c}\text { Inclinometer } \\
\text { (earth) }\end{array}$ & & SIS & $\begin{array}{c}24 \\
\mathrm{~mm}\end{array}$ & $\begin{array}{c}30 \\
\mathrm{~mm}\end{array}$ \\
\hline \multirow{2}{*}{2} & \multirow{2}{*}{$\begin{array}{l}\text { Structure } \\
\text { movement \& } \\
\text { deformation }\end{array}$} & $\begin{array}{l}\text { Electronic } \\
\text { beam sensor }\end{array}$ & (L) & BS & $\begin{array}{c}80 \% \text { of } \\
\text { action } \\
\text { level }\end{array}$ & $1.2 \%$ \\
\hline & & $\begin{array}{l}\text { Electronic } \\
\text { tiltmeter }\end{array}$ & & ETI & $\begin{array}{c}80 \% \text { of } \\
\text { action } \\
\text { level }\end{array}$ & $\begin{array}{l}1.2 \% 0 \\
(\sim 250 ")\end{array}$ \\
\hline 3 & $\begin{array}{l}\text { Groundwater } \\
\text { table \& } \\
\text { hydraulic } \\
\text { pressure }\end{array}$ & $\begin{array}{l}\text { Electronic } \\
\text { transducer } \\
\text { piezometer }\end{array}$ & $\cap$ & ELP & $\begin{array}{c}\text { See } \\
\text { Note } \\
(1)\end{array}$ & $\begin{array}{c}1 \mathrm{~m} \\
\text { above } \\
\text { alert } \\
\text { level }\end{array}$ \\
\hline
\end{tabular}

Note: (1) level that meets the requirement against piping and uplift failure; (2) d: depth of instrument installed; L: length of instrument

For the results of the electronic tiltmeters (Fig. 10), a general increase in magnitude was observed for both normal and tangential directions as the process was undertaken. A maximum of about +40 and -120 seconds was obtained from the instrument mounted on the up-track tunnel side (i.e. ETI 40002) for normal and tangential directions, respectively. The maximums were still within the response levels (i.e. 200 seconds for alert and 250 seconds for action) as shown in Table 2. The trend tends to rebound approximately right after the construction of invert was completed and the installation of track plinths just began. While a residual value of about -50 seconds was retrieved at the instrument ETI 40002 for the tangential direction at the end of flood wall and dust-free, soundproof wall demolition, the rest of the readings had almost returned to the initial values.

As to the electronic beam sensors, Fig. 11 illustrates that the settlements tend to slightly increase in magnitude as the construction was in progress. Since

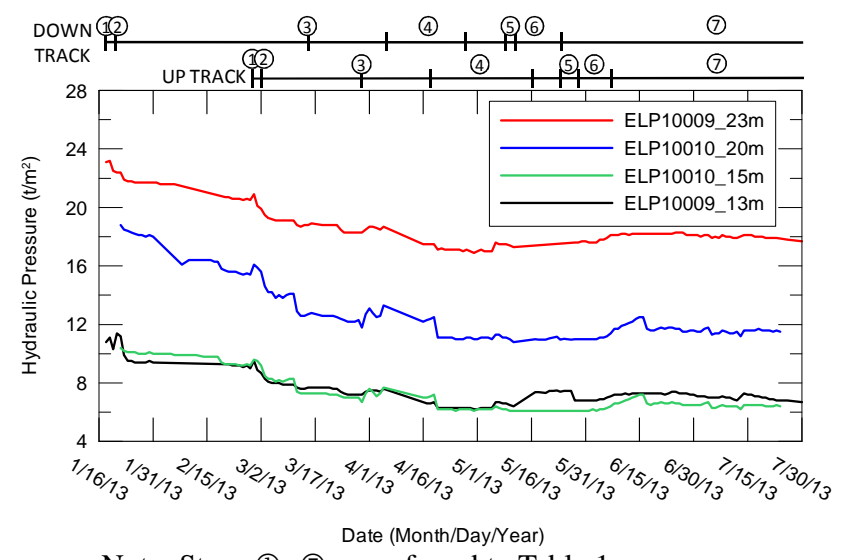

Note: Steps (1) (7) are referred to Table 1.

Fig. 9 Hydraulic pressure distribution over construction period.

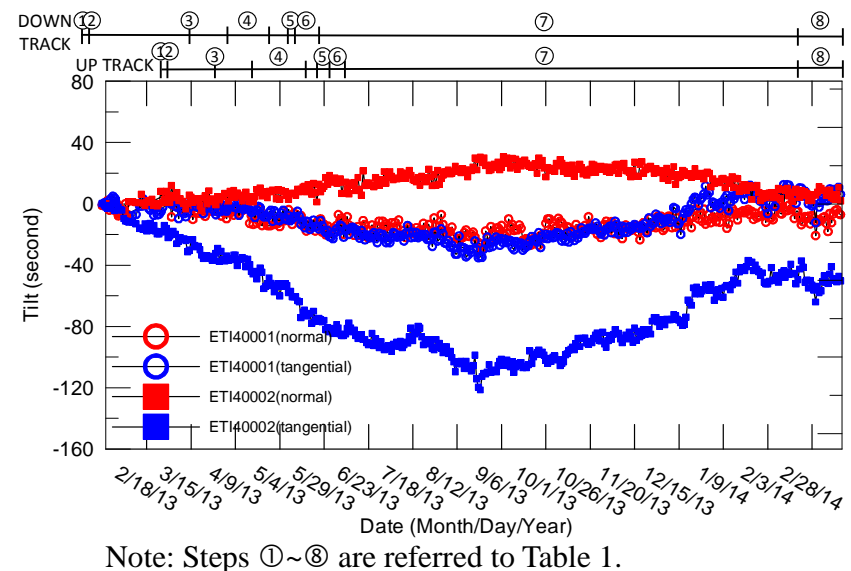

Fig. 10 Tiltmeter results over construction period.

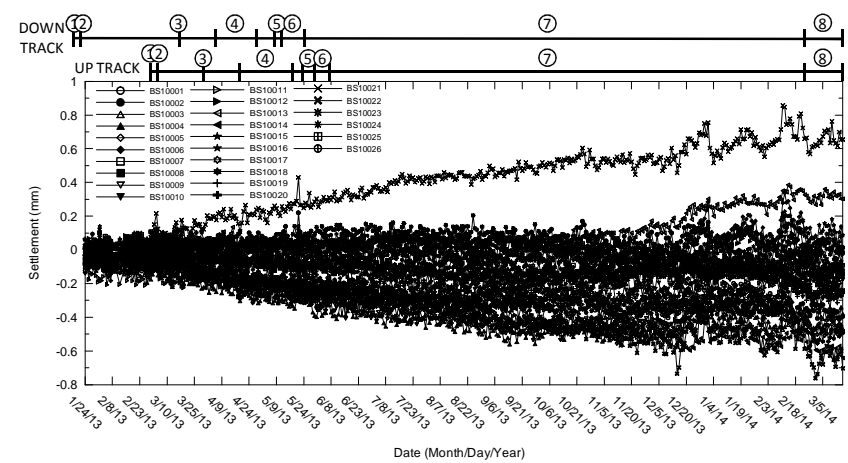

Note: Steps (1) (8) are referred to Table 1.

Fig. 11 Beam sensor results over construction period.

the maximum falls within a range between $+0.8 \mathrm{~mm}$ and $-0.8 \mathrm{~mm}$, the maximum tilt between sensors is about $0.8 \%$ o that is smaller than the associated alert $(0.96 \%$ ) and action $(1.2 \%$ ) levels.

\section{CONCLUSIONS}

Shield machines arriving at an operating station are a complex and challenging job in soft ground engineering. It requires a thorough plan to incorporate the operating authority's requirement into the construction procedure that includes not only confirmation of ground improvement quality but machine disassembly, lining erection, wall demolition, and HVAC/E\&M connection as well. The study case of the paper was finished under the condition that the construction effects on the ground or structure deformations were all under the associated response levels. In addition, the induced dust, vibration, and noise did not interrupt the station's operation. It is thus provided as a reference for the similar cases.

\section{ACKNOWLEDGEMENTS}

Permission for publishing this paper from Moh and Associates, Inc. and Department of Taipei Rapid Transit Systems (DORTS) of Taipei City Government is gratefully appreciated. Special thanks to Miss 
Jia-Rong Lyu who helped prepare the figures.

\section{REFERENCES}

1) Cheng, S. H., Wong, Ricky K. N. and Liao, H. J. (2012): A large diameter jet grouting method for arrival of shield tunneling machine, Proceedings of the International Symposium \& Short Courses: Recent Research, Advances \& Execution Aspects of Ground Improvement Works, Brussels, Belgium, 4, 205-214.

2) DORTS (2014): Taipei MRT, Brochure, Department of Rapid Transit Systems, Taipei City Government, 40.

3) MAA (2008): General assessment of the planning and construction methods in shield tunneling for Tucheng Line project extension Dingpu (Design Lot 170) of Taipei metropolitan area rapid transit system, Report, Moh and Associates, Inc., 300 (in Chinese).

4) MAA (2009): Complementary site investigation report for Tucheng Line project extension Dingpu (Design Lot 170) of Taipei metropolitan area rapid transit system, Report, Moh and Associates, Inc., 285 (in Chinese). 